\title{
Ultra-Fine Grained High Carbon Steel by Innovative Deformation
}

\author{
A.W.F. Smith ${ }^{1, a}$, D.N. Crowther ${ }^{1, b}$, P.J. Apps ${ }^{2, c}$ and P.B. Prangnell ${ }^{3, d}$ \\ ${ }^{1}$ Corus Research, Development \& Technology, Swinden Technology Centre, Moorgate, \\ Rotherham, South Yorkshire, S60 3AR, UK \\ ${ }^{2}$ Health \& Safety Laboratory, Harpur Hill, Buxton, Derbyshire, SK17 9JN, UK \\ ${ }^{3}$ Manchester Materials Science Centre, University of Manchester, Grosvenor Street, Manchester, \\ M1 7HS, UK \\ aandrew.x.smith@corusgroup.com, ${ }^{b}$ dave.crowther@corusgroup.com, ${ }^{c}$ pete.apps@hsl.gov.uk, \\ philip.prangnell@manchester.ac.uk
}

Keywords: Ultra-fine grain, EBSD, high carbon steel

\begin{abstract}
It is well known that the refinement of grain size in metals leads to a significant improvement in specific mechanical properties. Processing schedules have been investigated aimed at producing an homogeneous ultra-fine ferrite and spheroidised carbide aggregate microstructure in high carbon $(\mathrm{CMn})$ steels $(0.6-1.2 \mathrm{wt} \% \mathrm{C})$, via conventional 'warm' rolling and innovative Equal Channel Angular Extrusion (ECAE). Suitable deformation schedules were determined from dilatometry and thermo-mechanical Gleeble simulations. Evidence of an ultra-fine ferrite and carbide aggregate microstructure following 'warm' rolling was observed. A significant improvement in tensile strength, particularly proof stress was also noted in comparison to material deformed at higher temperatures. Concurrent ECAE experiments investigated microstructural evolution with incremental strain. Extensive analysis was carried out using various techniques, including high resolution Electron Back Scattered Diffraction (EBSD). Evidence of ferrite grain refinement was noted in a eutectoid composition steel. A sub-micron ferrite structure was observed following high strains $(\varepsilon \sim 3.33)$ and the mechanical properties exhibited a marked increase in tensile strength.
\end{abstract}

\section{Introduction}

The refinement of grain size has long been perceived as the ideal strengthening mechanism in steels. Ultra-fine grained steels have been the subject of much research over the past decades $[1,2]$ due to the potential property benefits that exist. An increase in both strength and toughness can be observed, without recourse to expensive alloying additions or complicated heat treatment. Weldability and even recyclability are improved, suggesting that an ultra-fine microstructure is without drawback. Unfortunately this is not the case. History has shown that ferrite grain refinement beyond the $4-5 \mu \mathrm{m}$ mark has proved difficult following standard commercial practices, in spite of successful laboratory and pilot based studies [3]. In more recent years, the culmination of a number of substantial worldwide research programmes have shown that realisation of a submicron $(<1 \mu \mathrm{m})$ grain size is now achievable through hot rolling. However, pertinent questions regarding the suitability and, more importantly, the mechanical stability of steel with ultra-fine grains still remain. For example, although extremely strong in comparison to coarser grained material, minimal work hardening is observed that is often accompanied by unstable yielding [4,5]. In light of these observations, the present work involving high carbon steels $(0.6-1.2 \mathrm{wt} . \% \mathrm{C})$ has explored process routes capable of generating a two-phase ultra-fine ferrite and carbide aggregate (UFF-CA) microstructure with ferrite grain sizes in the order of $\sim 2-3 \mu \mathrm{m}$, signalling a 'back-track' away from the previously much vaunted sub-micron grain size. 


\section{Experimental method}

A range of simple high carbon (0.6-1.2wt.\%), manganese and silicon alloys, including a eutectoid composition, were chosen for the investigation. Details of the compositions are given in Table 1.

Table 1. Chemical composition of high carbon experimental alloys (wt.\%)

\begin{tabular}{ccccccc}
\hline $\mathrm{C}$ & $\mathrm{Si}$ & $\mathrm{Mn}$ & $\mathrm{P}$ & $\mathrm{S}$ & $\mathrm{Al}$ & $\mathrm{N}$ \\
\hline 0.61 & 0.20 & 0.69 & 0.016 & 0.005 & 0.031 & 0.0057 \\
0.81 & 0.20 & 0.70 & 0.015 & 0.004 & 0.031 & 0.0062 \\
1.22 & 0.20 & 0.69 & 0.016 & 0.005 & 0.030 & 0.0069 \\
\hline
\end{tabular}

A $65 \mathrm{~kg}$, approximately $125 \mathrm{~mm}$ square ingot, was cast for each carbon level. The ingots were reheated to $\sim 1200^{\circ} \mathrm{C}$, held at temperature for four hours prior to rolling as rapidly as possible to $75 \mathrm{~mm}$ plate to reduce segregation and consolidate porosity. Finish roll temperatures of $\sim 1050^{\circ} \mathrm{C}$ were recorded for all ingots. Samples were machined from each rolled plate and their transformation characteristics assessed in a Bahr 105 dilatometer. Cylindrical samples (10x6mm) were prepared for uni-axial compression testing on a Gleeble 1500 thermo-mechanical simulator to determine suitable rolling schedules to produce the desired ultra-fine microstructure. Small blocks $(150 \times 75 \times 75 \mathrm{~mm})$ for further rolling experiments were furnace reheated and homogenised at $1150^{\circ} \mathrm{C}$, then rolled to either a thickness of $\sim 62$ or $50 \mathrm{~mm}$, with an aim temperature of $900^{\circ} \mathrm{C}$, in preparation for strains of $\sim 1.2$ or $\sim 2$ (respectively) to be introduced during finish rolling. The samples were then air-cooled until the temperature reached the final deformation temperature, i.e. $700^{\circ} \mathrm{C}$ or $600^{\circ} \mathrm{C}$ before several finish roll passes were applied. Final aim gauge was $7 \mathrm{~mm}$. Cylindrical billets, $100 \mathrm{~mm} \times 15 \mathrm{~mm}$ diameter, were machined from the plates in the rolling direction and processed by ECAE at a constant $500^{\circ} \mathrm{C}$. Graphite lubrication was used and the billets were heated at $50^{\circ} \mathrm{C} / \mathrm{min}$ and held at temperature for 15 minutes prior to processing. A circular cross-section ECAE die was used with a die angle of $120^{\circ}$, giving a nominal von Mises' effective strain of $\varepsilon_{\mathrm{vm}} \sim 0.67$ per pass. The deformation structures were characterised using SEM metallography and high resolution EBSD. Tensile properties were determined for both rolled and ECAE deformed material. Two tensile test pieces were machined from the centre of each rolled plate and from each ECAE processed billet.

\section{Results and discussion}

Deformation by warm rolling to conventional strains. Schedules for hot rolling were devised based upon the results of the Gleeble simulations. Deformation temperatures of 700 and $600^{\circ} \mathrm{C}$ and finishing strains of $\sim 1.2$ and 2 were implemented with a cooling rate of approximately $<5^{\circ} \mathrm{C} / \mathrm{s}$. After deformation at $700^{\circ} \mathrm{C}$ (above $\mathrm{Ar}_{3}$ ), a typical pearlite microstructure was produced in all cases. Substantial areas of grain boundary ferrite were evident in the $0.6 \mathrm{wt} . \% \mathrm{C}$ steel. The $0.8 \mathrm{wt} . \% \mathrm{C}$ steel was characterised by a fully pearlitic microstructure and increasing the carbon content to $1.2 \mathrm{wt} . \% \mathrm{C}$ led to the formation of cementite laths at prior austenite grain boundaries. A partially spheroidised microstructure was often found at sub-surface regions in each of the steels, particularly in the lower strained samples (i.e. $~ 1.2$ ). This was attributed to accelerated local cooling, possibly due to roll chill, which had led to transformation during deformation, and/or discrete strain localisation. Small 'pockets' of lamellar cementite, thought to be due to localised temperature differences, were also apparent in the mid-thickness of samples deformed at $600^{\circ} \mathrm{C}$. In general, an ultra-fine ferrite and spheroidised carbide structure was evident following deformation at $600^{\circ} \mathrm{C}$ to a strain of $\sim 2$.

High resolution EBSD was carried out to determine the nature of the boundaries observed in the ferrite matrix in the rolled sample, and corresponding statistics. An example EBSD Euler angle map for the $0.6 \mathrm{wt} . \% \mathrm{C}$ steel rolled at $600^{\circ} \mathrm{C}$ to a strain of $\sim 2$ is given in Figure 1. A fine step size of $0.1 \mu \mathrm{m}$ was used so that accurate subgrain information could be obtained (Fig. 1). 
Figure 1 shows that after deformation by controlled rolling the ferrite did not have what could be described as an ultra-fine grain structure, and predominantly contained elongated fibrous grains with subgrains. Some relatively large grains containing low angle grain boundaries (LAGBs) were evident, which were considered to correspond to areas of pro-eutectoid ferrite (Fig. 1). Some bands of finer, ferrite grains were observed adjacent to these areas, aligned in the rolling direction (Fig. 1), formed as a consequence of the pearlitic spheroidisation. EBSD statistical boundary data confirmed that an ultra-fine structure consisting of both low angle and high angle grain boundaries was achieved following deformation at $600^{\circ} \mathrm{C}$ to a strain of $\sim 2$. The majority of the boundaries present were low angle; between 1.5 and $15^{\circ}$ misorientation (58\%) and approximately $40 \%$ could be described as high angle grain boundaries (HAGBs) i.e. in excess of $15^{\circ}$ misorientation. The average grain boundary spacing was $2.19 \mu \mathrm{m}$ and subgrain spacing $1.14 \mu \mathrm{m}$. However, it should be noted that $>75 \%$ of the boundaries had a misorientation in excess of $5^{\circ}$, suggesting that the sub-structure was well developed.

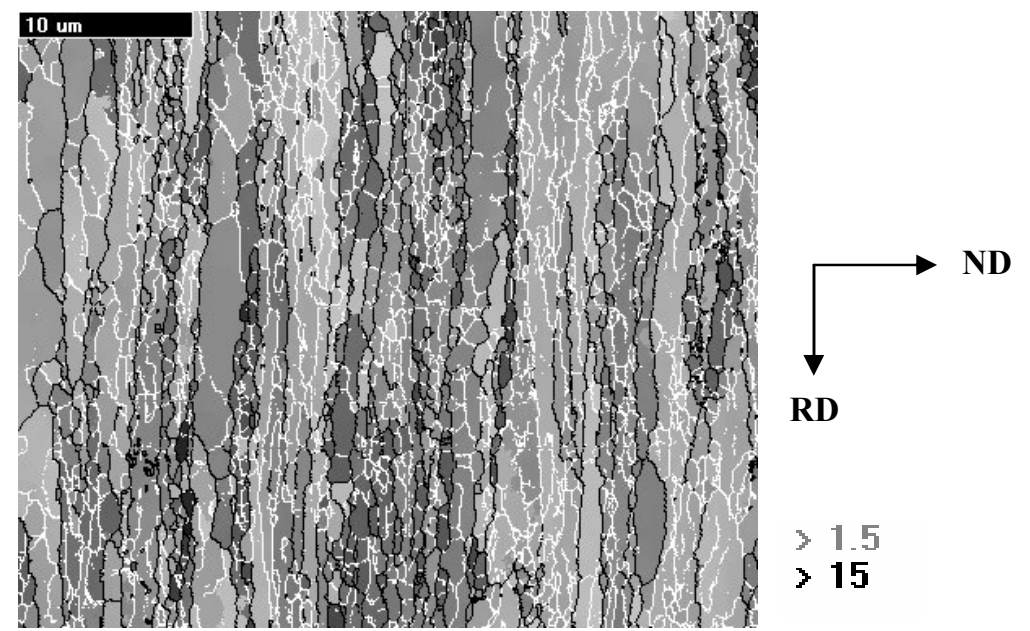

Figure 1. EBSD orientation map of $0.6 \mathrm{wt} . \% \mathrm{C}$ steel following rolling at $600^{\circ} \mathrm{C}, \varepsilon \sim 2$.

Mechanical properties. Tensile properties were determined for each of the steel compositions. Figure 2 shows example results for the $0.8 \mathrm{wt} . \% \mathrm{C}$ steel. In all cases a marked increase in proof stress (PS) was observed, particularly at deformation temperatures of $600^{\circ} \mathrm{C}$ (Fig. 2). In general, UTS values were greater after deformation at $600^{\circ} \mathrm{C}$ in comparison to the 'Normal' material (rolled at $1050^{\circ} \mathrm{C}$ ) and $700^{\circ} \mathrm{C}$ (Fig. 2). No obvious relationship was present between deformation and elongation in any of the steels. It should be noted that samples deformed at $600^{\circ} \mathrm{C}$ exhibited higher PS:UTS ratios, however unstable yielding was not evident and a substantial increment of work hardening was retained in contrast to many other ultra-fine 'grained' materials $[4,5]$.

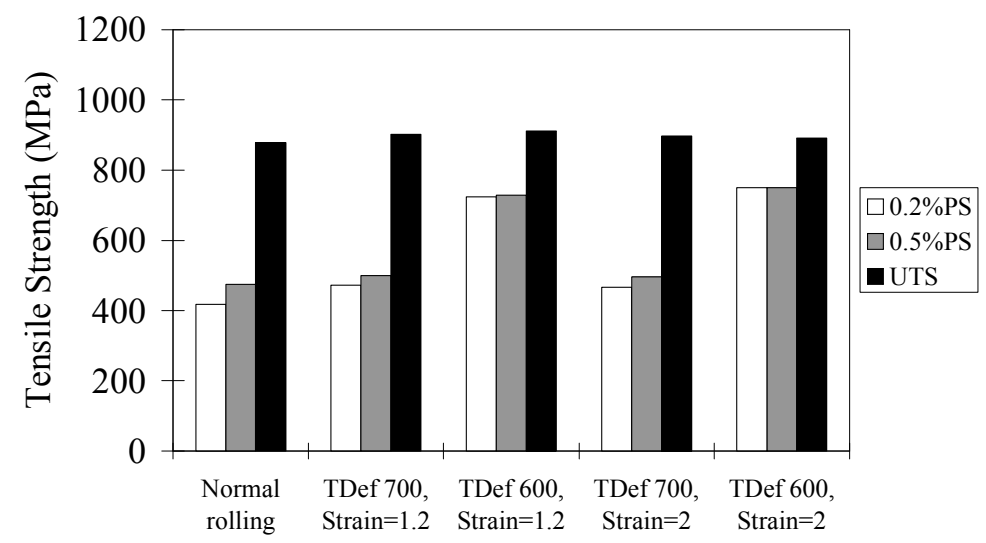

Figure 2. Tensile property data for $0.8 \mathrm{wt} . \% \mathrm{C}$ steel following rolling trials 
ECAE to high strains. ECAE processing was used to investigate the advantages of a shear deformation mode and to study the effect of increasing the deformation strain beyond that achievable by rolling. High resolution $(0.1 \mu \mathrm{m}$ step size) EBSD was carried out to determine the extent of grain refinement in the $0.8 \mathrm{wt} . \% \mathrm{C}$ steel with increasing strain. Figure 3 shows example Euler orientation maps that illustrate the microstructural evolution for the $0.8 \mathrm{wt} . \% \mathrm{C}$ steel. As strain increased, a high density of HAGBs developed leading to a submicron HAGB spacing by a strain of 3.3 (see Fig. 3(a) - (c)). Considerable refinement was evident after 3 passes (Fig. 3(b)), with 'ribbons' of refined ferrite grains forming in the extrusion direction, containing well defined subgrains. With increased deformation, the HA and LAGB spacing continued to reduce and the structure became more equiaxed in appearance (Fig. 3(c)). However, the EBSD maps (Fig. 3(a) (c)) also indicated that this 'refinement' was quite heterogeneous in nature and that the structure only became relatively homogeneous following large deformation strains (i.e $\varepsilon_{\mathrm{vm}} \sim 3.33$ ). Following a strain of $\varepsilon_{\mathrm{vm}} \sim 3.33$ (5 passes), a sub-micron grain size was observed $(\sim 0.7 \mu \mathrm{m})$ and the HAGB content was approximately $60 \%$. A plot illustrating the reduction of HAGB spacing and increase in HAGB percentage area with increasing deformation is shown in Figure 4. Apps et al [6] have observed similar findings during the refinement of a particle containing aluminium alloy.
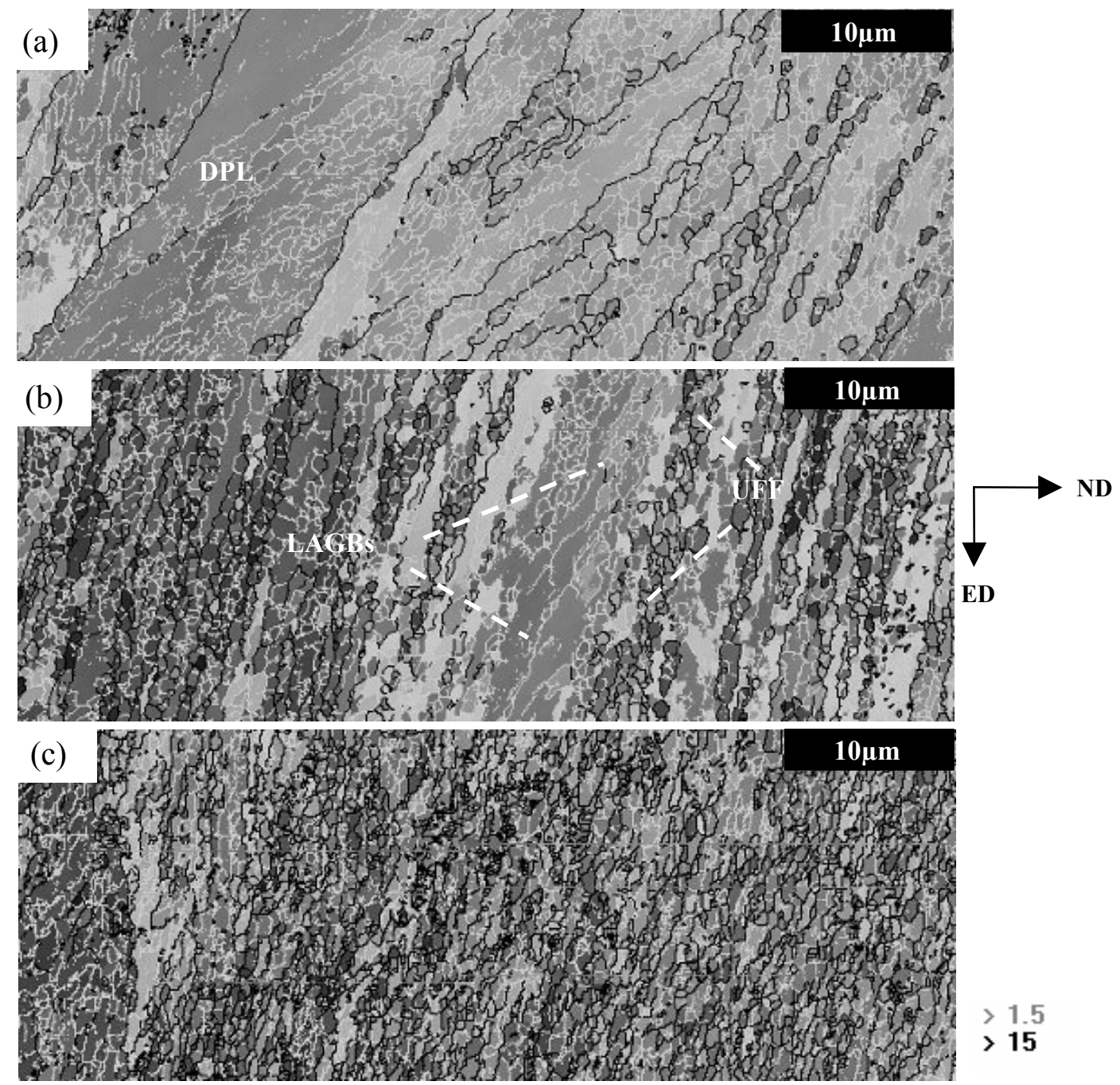

Figure 3. EBSD maps of the $0.8 \mathrm{wt} . \% \mathrm{C}$ steel after (a) 1, (b) 3 and (c) 5 ECAE passes. Areas of deformed pearlite lamellar (DPL), ultra-fine ferrite (UFF) and low angle grain boundaries (LAGBs) are indicated. 


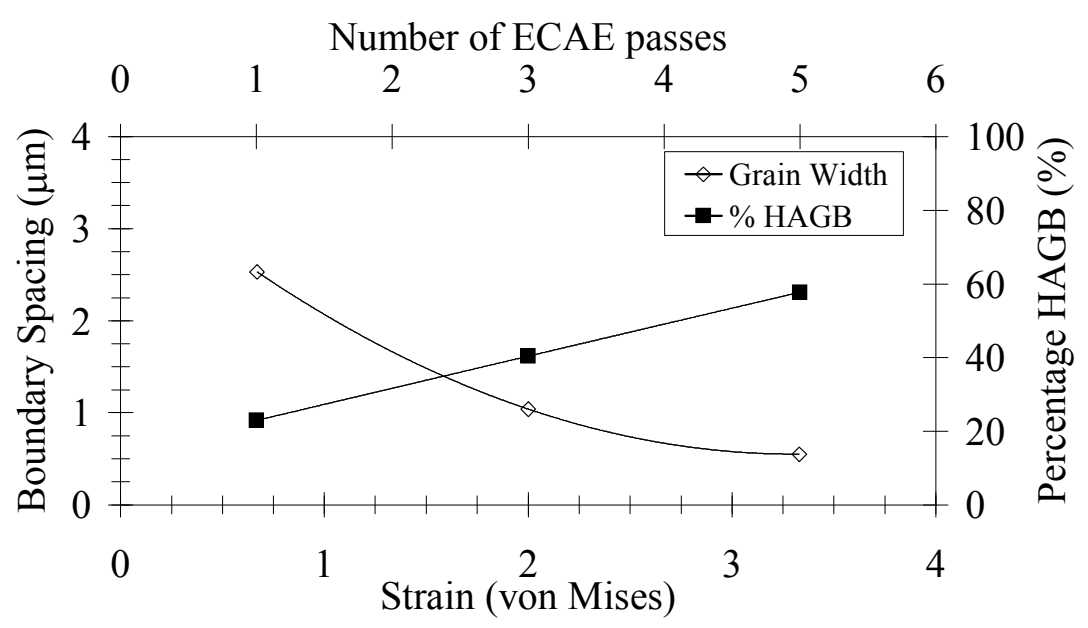

Figure 4. EBSD statistical data for $0.8 \mathrm{wt}$.\% $\mathrm{C}$ steel as a function of strain during ECAE processing.

Analogous EBSD analysis was carried out on the 0.6 and $1.2 \mathrm{wt} . \% \mathrm{C}$ steels following ECAE deformation to 5 passes $\left(\varepsilon_{\mathrm{vm}} \sim 3.33\right)$. A refined substructure was evident in the $0.6 \mathrm{wt} . \% \mathrm{C}$ steel after 5 passes, yet there was little HAGB content $\sim 30 \%$, particularly in comparison to the $0.8 \mathrm{wt} . \% \mathrm{C}$ steel $(\sim 60 \%)$ following the same amount of deformation. It is thought that this lack of HAGB generation and refinement may be due to the majority of the initial deformation being concentrated in the areas of primary ferrite rather than the pearlite lamellar areas, leaving a relatively large HAGB spacing or grain size. Evaluation of the $1.2 \mathrm{wt} . \% \mathrm{C}$ steel after $5 \mathrm{ECAE}$ passes also suggested that refinement proceeded at a 'slower' pace in comparison to the $0.8 \mathrm{wt} \% \mathrm{C}$ steel. No evidence for accelerated, homogeneous refinement due to large cementite particles was noted, excluding the obvious matrix refinement observed in the immediate vicinity of those particles.

Mechanical properties. Similar tensile behaviour was observed in all the steels as a function of strain and example data is given in Figure 5 for the $0.8 \mathrm{wt} . \% \mathrm{C}$ steel. In each case, a large increase in proof stress and a lesser increase in UTS was observed following the first ECAE pass (Fig. 5). Subsequent passes resulted in a slower increase in proof stress and plateau in UTS values with the two values tending to converge at high levels of deformation. Elongation values tended to show more scatter, but in general a decrease with increasing deformation was observed. The results suggested that although an increase in tensile strength was clearly apparent, it was somewhat to the detriment of work hardening, ductility and also the advent of plastic instability and associated phenomena. Such high ratios of PS:UTS are common in ultra-fine grained materials and occur as the subgrain size approaches that of the grain size.

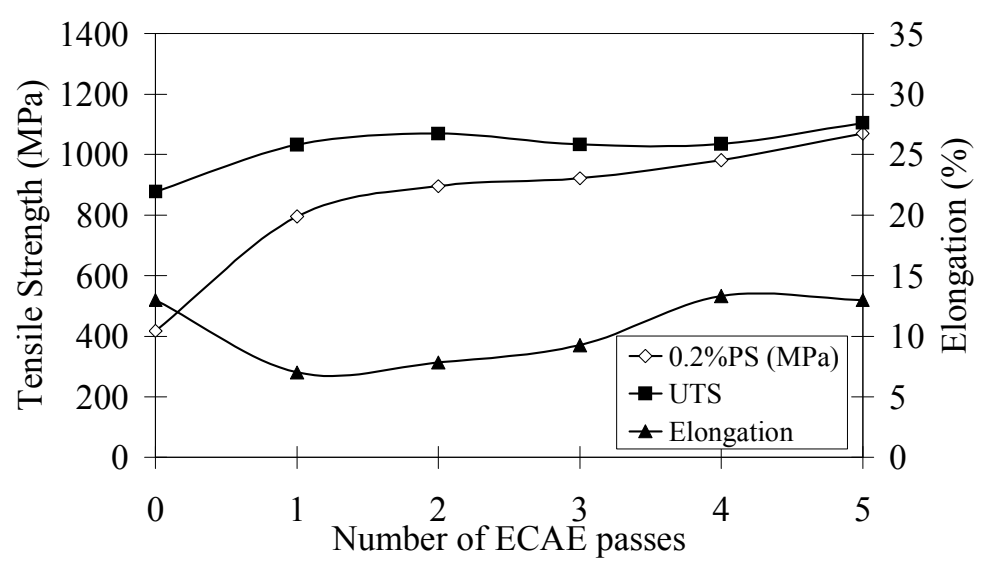

Figure 5. Tensile properties of $0.8 \mathrm{wt} . \% \mathrm{C}$ steel with increase in ECAE deformation 


\section{Summary}

Efforts to produce a two-phase ultra-fine grained structure in high carbon (0.6-1.2wt.\%) steels through innovative deformation have proved successful. Deformation strains of $\sim 1.2$ induced during warm rolling at $\sim 600^{\circ} \mathrm{C}$ were sufficient to promote carbide spheroidisation and refinement of the ferrite matrix. Quantitative EBSD measurements record a grain size in the order of $\sim 2 \mu \mathrm{m}$ and corresponding subgrain size of $\sim 1 \mu \mathrm{m}$. A marked increase in strength, particularly proof strength, was noted and a substantial increment of work hardening is retained.

ECAE deformation illustrated that pearlite spheroidisation occurred in each steel following two passes. An ultra-fine ferrite and carbide aggregate structure was observed after four passes. Ferrite grain refinement occurs more rapidly in a pearlitic eutectoid composition $(0.8 \mathrm{wt} . \% \mathrm{C})$ steel, resulting in a submicron grain size following moderate deformation strains ( $\sim 5$ passes). The presence of coarse cementite particles in the $1.2 \mathrm{wt} . \% \mathrm{C}$ steel was observed to promote development of high misorientation boundaries within their immediate vicinity. However, due to the large and relatively un-deformable nature of the cementite particles in comparison with the 'soft' ferrite matrix, much of the initial grain refinement was limited to these deformation zones and overall HAGB formation and grain refinement proceeded at a slower rate. Slow grain refinement observed in the $0.6 \mathrm{wt} . \% \mathrm{C}$ steel was considered a result of the single phase, primary ferrite regions 'absorbing' the majority of the imparted deformation, leaving the pearlite deformed to a lower effective strain. A large increase in tensile strength was observed following the initial ECAE pass. Subsequent deformation resulted in a lesser increase in proof stress and UTS values plateau following two passes.

\section{Acknowledgements}

The authors would like to thank Corus Research, Development \& Technology for permission to publish this work. It should be noted that the work has been part funded with a financial grant from the European Coal and Steel Community.

\section{References}

[1] H. Dong: Ultra-fine Grained Steels and Properties, International Symposium on Ultrafine Grained Steels (2001), p. 18.

[2] C. Ouchi, International Forum on Creation of Super Metallic Materials, Tokyo, RIMCOF \& JRCM (1997), p. 937.

[3] R. Priestner and A.K. Ibraheem: Processing of steel for ultrafine ferrite grain structures, Mater. Sci. \& Tech. Vol. 16 (2000), p. 1267-1272.

[4] W.B. Morrison and R.L. Miller: The Ductility of Ultrafine Grained Alloys, Ultrafine-Grain Metals, J.J. Burke and V. Weiss, Eds., Syracuse University Press (1970), p. 183.

[5] P.D. Hodgson, M.R. Hickson and R.K. Gibbs: The Production and Mechanical Properties of Ultrafine Ferrite, Mater. Sci. Forum Vols. 284-286 (1998), p. 63.

[6] P.J. Apps, J.R. Bowen and P.B. Prangnell: The effect of coarse second-phase particles on the rate of grain refinement during severe deformation processing, Acta Mater. Vol. 5110 (2003), p. 2811. 